\title{
NICOLLO MACHIAVELLI: SANG BELIS POLITIK? Suatu Refleksi Dan Kritik Filosofis Terhadap Gagasan Politik Machiavelli Dalam Il Principe
}

\section{E. Fernando M. Manullang ${ }^{1}$}

\begin{abstract}
Abstrak
Machiavelli was one of the groundbreaking philosopher of medieval philosophical tradition that is influenced by a metaphysical perspective. Perspective Machiavelli's is secular in politics and his attitude was critical of the moral, fundamentally also influenced his views on leadership and the state. Machiavelli emphasized the aspect of personality in a leader. A leader can be powerful only if the leaders understand exactly about the importance of skill and talent or the strength required by a leader in the lead. For Machiavelli, a leader one must understand how to expand and defend the territory of his kingdom, then he should be able to use that crime does not continue in seizing the state. Il Principe Machiavelli's observations are based on the pattern of power management that is run Cesare Borgia, the eldest son of Alexander VI with Vannoza de Cateneis.
\end{abstract}

Kata kunci: filsafat, il principe, politik

\section{Pendahuluan}

Jika kita mendengar suatu nama: Machiavelli, kebanyakan orang awam politik meyimpulkan bahwa nama itu setara dengan berandal atau belis. Lord Macaulay (1800-1859) misalnya, seorang sejarawan, politisi dan penyair Inggris, ${ }^{2}$ pernah mengatakan dalam tulisannya, Essays Contributed to the Edinburgh Review (1843); "Out of his surname they have coined an

1 Staf Pengajar Fakultas Hukum Universitas Indonesia. Alamat kontak: nando@ui.ac.id.

${ }^{2}$ Dikenal waktu lahir dengan nama Thomas Babington. Ia aktif terlibat dalam gerakan menentang perbudakan, pendukung pendidikan dan persamaan hak di India dan reformasi parlemen untuk meningkatkan keterwakilan desa selama masa pertumbuhan industrial. Macauly menulis 5 volume buku sejarah Inggris dan menulis beberapa esai kritis. Lihat dalam <http://oll.libertyfund.org/?option=com_staticxt\&staticfile=show.php $\% 3 \mathrm{~F}$ person $=80 \&$ Itemid $=28>$, diakses 24 November 2009 . 
ephitet for a knave, and out of his Christian name a synoym for the Devil". 3 Kalaupun bukan hinaan bagi Machiavelli, Victor Hugo (1802-1885), seorang penyair asal Perancis, ${ }^{4}$ pernah mengatakan secara datar tanpa apresiasi apapun mengenai dirinya. Demikian kata Hugo dalam karyanya, Les Misérables $;^{5}$

\begin{abstract}
Machiavelli is not an evil genius, nor a cowardly and miserable writer, he is nothing but the fact. And he is not merely the Italian fact, he is the European fact, the fact of the sixteenth century. He seems hideous, and is so, in presence of the moral idea of the nineteenth.
\end{abstract}

Dibalik sikap yang demikian terhadap Machiavelli, ada juga simpati yang diberikan kepadanya. Salah satunya adalah Francis Bacon (1516-1626) yang secara positif pernah menyatakan Machiavelli dalam bukunya The Advancement of Learning (1605); "We are much beholden to Machiavel and others, that write what men do, and not what they out to do". ${ }^{6}$

Kontroversi semacam itu uniknya hampir tidak ditemukan dalam beberapa literatur hukum di Indonesia. Kebanyakan literatur tersebut memiliki kesan atau tudingan yang seragam mengenai Machiavelli; seorang belis politik memuja kekuasaan dan menghalalkan segala cara untuk merawat kekuasaannya. Hal ini bisa dilihat umpamanya dalam karya M. Kusnardi dan Profesor Bintan R. Saragih. Keduanya menjelaskan bahwa didalam tulisan Machiavelli: Il principe, Machiavelli menekankan pentingnya unsur

3 Lihat Susan Ratcliffe (ed.), "People on People: The Oxford Dictionary of Biographical Quotations", (Oxford: Oxford University Press, 2001), hal. 228.

${ }^{4}$ Lahir pada 26 Februari 1802 . Hugo dikenal juga sebagai seorang negarawan yang memperjuangkan kebebasan pers, penghapusan hukuman mati dan ketidakadilan sosial, selain pendukung kemerdekaan negara Polandia. Ia seorang sekuler dalam urusan agama. Ia pernah hidup terbuang di Belgia, ketika Napoleon merebut kekuasaan di Perancis. Saat masa pembuangan, ia menulis sebuah pamflet politik yang menyudutkan kekuasaan Napoleon. Walau dia dianugerahi pengampunan oleh Napoleon, Hugo menolaknya, hingga suatu saat ia bisa kembali ke Paris. Sekembalinya ke Paris, ia berusaha untuk menjadi anggota parlemen. Saat yang bersamaan, ia menghadapi nasib yang malang, anak perempuannya dimasukkan ke rumah sakit jiwa dan 2 putranya wafat. Istri dan gundik setianya pun meninggal. Hal itu tidak menyurutkan niatnya untuk menjadi anggota senat. Pada $22 \mathrm{Mei} 1885$, ia tutup usia. Lihat dalam <http://www.hugo-online.org/victor_hugo_biography.html>, diakses 25 November 2009.

\footnotetext{
${ }^{5}$ Lihat Susan Ratcliffe (ed.), Op. Cit., hal. 228.

${ }^{6}$ Lihat Susan Ratcliffe (ed.), Ibid., hal. 228.
} 
kekuasaan dalam negara. Pemerintahan tidak lebih dari sebuah upaya memeroleh kekuasaan dan melaksanakan kekuasaan tersebut. ${ }^{7}$ Selain itu, Profesor Kranenburg dan Tk. B. Sabaroedin memiliki intonasi yang nyaris serupa dengan sebelumnya. Menurut pemahaman merka berdua, Machiavelli menyatakan bahwa suatu pemerintahan yang baik, pasti akan binasa, itu tidak cocok/asing dengan sistemnya dan lambat laun suatu saat akan disepak dari keluarganya. ${ }^{8}$ Lalu, senada dengan tudingan-tudingan sebelumnya, Profesor Azhary pun mengatakan bahwa; ${ }^{9}$

..., untuk mencapai tujuan negara, ia $^{10}$ menyarankan, bilamana perlu kepala negara tidak usah terlampau memperhatikan moral, ia boleh berlaku tidak jujur, boleh ingkar janji, kejam, kikir dan mendustai kepercayaan terhadap Agama. Asal saja semuanya itu dilakukan untuk memperbesar atau mempertahankan kekuasaannya.

Sementara itu, Profesor Solly Lubis memberikan kesan yang mengerikan tentang pikiran Machiavelli, karena ia mengatakan bahwa Machiavelli telah memberikan suatu ajaran, diantaranya; setiap perlawanan terhadap pemerintah harus ditindas dengan benar-benar. ${ }^{11}$ Lebih mengerikan lagi daripada yang diutarakan sebelumnya, M. Hutauruk menuding bahwa ajaran Nicollo Machiavelli dipraktekkan dalam sistem politik kaum fasis di Italia. ${ }^{12}$

${ }^{7}$ Lihat dalam hal. Moh. Kusnardi dan Bintan R. Saragih, "Ilmu Negara", Edisi Revisi (Jakarta: Penerbit Gaga Media Pratama, 1995), hal. 72-73. Hendra Nurtjahjo kurang lebih mengatakan hal yang sama bahwa ada hubungan yang erat antara negara dan kekuasaan. Membangun negara adalah sama dengan membangun kekuasaan secara efektif menurut Machiavelli, lihat dalam Hendra Nurtjahjo, "Ilmu Negara: Pengembangan Teori Bernegara dan Suplemen", (Jakarta: RajaGrafindo Persada, 2005), hal. 25. Bdk. Djokosutono, "Ilmu Negara", ed. Harun Al Rasyid (Jakarta: Ghalia Indonesia, 1982), hal. 73.

${ }^{8}$ Lihat dalam R. Kranenburg dan Tk. B. Sabaroedin, "Ilmu Negara Umum", Cetakan Kesebelas (Jakarta: Prádnya Paramita, 1989), hal. 60.

${ }^{9}$ Lihat Azhary, "Negara Hukum Indonesia: Analisis Yuridis Normatif tentang Unsur-Unsurnya", (Jakarta: Penerbit Universitas Indonesia, 1995), hal. 22.

${ }^{10}$ Maksudnya disini adalah Machiavelli.

${ }^{11}$ Lihat M. Solly Lubis, Ilmu Negara, Cetakan ke-IV (tanpa kota: Penerbit Mandar Maju, 1990), hal. 45-47. 


\section{Permasalahan dan Lingkup Pembahasan}

Dengan situasi demikian, mari kita mengunjungi kembali pemikiran Machiavelli; agar kita dapat memahami cakrawala dan dimensi filsafatnya secara utuh dan kemudian menguji kembali, apakah memang Nicollo Machiavelli adalah seorang belis politik? Atau apakah tudingan itu malah buah dari pemahaman yang distortif atas pemikiran Machiavelli?

Lalu, jika diandaikan bahwa tafsir Machiavelli itu memang distortif, kritik sejati apa yang bisa kita berikan atas karya Machiavelli tersebut? Atau dengan kalimat yang lain, apa sesungguhnya kelemahan epistemologis karya Machiavelli tersebut?

Pengunjungan kembali pada pemikiran Machiavelli ini tidak berarti mengunjungi seluruh karya filosofis Machaivelli. Refleksi ini dibatasi pada karya Machiavelli yang kerap mendapatkan tudingan tidak enak; Il principe. Namun, apabila refleksi ini kemudian melebar pada karya Machiavelli yang lain, karena itu dirasakan ada relevansi yang komplemen sifatnya. Dikatakan komplemen, karena kenyataannya, fokus utama refleksi dan kritik disini adalah Il principe. Konsekuensinya, pemaparan pandangan filosofis Machiavelli dibawah, akan disajikan secara umum, tanpa menunjukkan secara detil pada karyanya tersebut.

12 Lihat M. Hutauruk, "Azas-Azas Ilmu Negara", Cetakan ke-3 yang direvisi (Jakarta: Penerbit Erlangga, 1983), hal. 100. Padahal dalam lingkup diskursus filosofis, negara fasis Italia semasa dipimpin oleh Mussolini tidak sama sekali mengutarakan secara vulgar bahwa fasisme itu didasarkan pada ajaran Machiavelli. Mussolini malah berlainan dengan Machiavelli, karena Mussolini menganjurkan sebuah ajaran ideal politik yang didasarkan pada nilai-nilai harmoni. Oleh sebab itu, suatu bentuk negara ideal dihadapan Mussolini harus berintikan pada paham Korporatisme, yang menjunjung tinggi keharmonian dalam sistem politik suatu negara. Lihat penjelasan ini dalam E. Fernando M. Manullang, "Koporatisme dan Undang-Undang Dasar 45: Intrepretasi Hukum Terhadap Teks Undang-Undang Dasar 1945 dan Risalah Sidang Badan Penyelidik Oesaha ${ }^{2}$ Kemerdekaan (BPUPK) dan Panitia Persiapan Kemerdekaan Indonesia (PPKI) tentang Pengaruh Nilai Korporatisme dalam Undang-Undang Dasar 1945”, (Bandung: Nuansa Aulia, 2010). Bdk. E. Fernando M. Manullang, Ide Negara Korporatis Menurut Soepomo \& Benito Mussolini: Suatu Refleksi Kritis Atas Pengaruh dan Implikasi Gagasan Korporatisme Dalam Undang-Undang Dasar 1945, Jurnal Hukum \& Pembangunan, Tahun Ke-38, No. 2 (April-Juni, 2008), hal. 301-315. 


\section{Pembahasan}

\section{A. Riwayat Hidup Machiavelli ${ }^{13}$}

Machiavelli lahir di Firenze, Italia, sebuah kota yang berkembang pesat akibat perdagangan Timur-Barat semasa Perang Salib. NegaraKota ini dikuasai oleh keluarga-keluarga aristokrat yang status sosialnya amat kuat karena merka menikmati rezeki yang amat besar dari kegiatan perdagangan di kota tersebut. Kota itu pun tumbuh megah dengan berbagai macam bangunan.

Pada masa itu, Firenze adalah sebuah negara-kota yang nyaris tidak pernah stabil kehidupan politiknya. Di masanya, terjadi beberapa kali perubahan sistem politik; dari monarki ke demokrasi, dan kemudian kembali ke monarki. Kawasan itu juga menjadi sasaran empuk kaum penyerang, yang terutama dari Perancis dan Spanyol, datang untuk merampok.

Bahkan, tahta kekuasaan pun menjadi rebutan keluarga Guelphi dan Ghibellin pada abad ke-13. Keluarga Guelphi didukung oleh kelas menengah kota itu, sementara keluarga Ghibelin didukung oleh kaum aristoktrat. Pertikaian itu pada akhirnya dimenangkan oleh keluarga Guelphi yang kemudian berkuasa hingga 1,5 abad lamanya. Namun kekuasaan ini tidak diemban dengan seyogyanya. Keluarga penguasa tersebut tidak memerhatikan nasib rakyatnya. Akibatnya, timbul keresahan sosial di kalangan rakyat kebanyakan di kota tersebut.

Situasi ini dimanfaatkan oleh keluarga Medici. Dengan memanfaatkan keresahan sosial tersebut, Cosimo de'Medici dengan lihainya memanfaatkan pengetahuan politik dan uangnya, ia berhasil memanas-manasi rakyat kebanyakan. Ia memanipulasi penderitaaan rakyat, dan tanpa ikutserta pemilihan umum, Medici berhasil

13 Riwayat hidupnya disarikan dari Ross King, "Machiavelli: Philosopher of Power", (London: HarperCollins, 2007). John Bernard, "Why Machiavelli Matters: A Guide in Citizenship in a Democracy", (Westport: Praeger Publishers, 2009), J. J. von Schmid, "Grote Denkers over Staat en Recht (van Plato tot Kant), atau Ahli-ahli Pemikir Besar tentang Negara dan Hukum (dari Plato sampai Kant)", terj. Wiratno dan Djamaluddin Dt. Singomangkuto (Jakarta: Pembangunan, 1959), hal. 107-115. Anthony J. Parrel, "Machiavelli, Nicollo," Cambridge Dictionary of Philosophy, Second Edition, ed. Robert Audi (Cambridge: Cambridge University Press, 1999), hal. 526. Nicholas Bunin and Jiyuan Yu, "The Blackwell Dictionary of Western Philosophy", (Malden: Blackwell Publishing Ltd., 2004), hal. 405. Felix Gilbert, "Machiavelli, Nicolo," Encylopedia of Philosophy, Second Edition, Vol. 5, ed. Donald M. Borchert (Detroit: Thomson Gale, 2006), hal. 626-629. 
mendapatkan dukungan rakyat dan terpilih menjadi penguasa baru kota tersebut.

Puncak kejayaan keluarga Medici itu terjadi pada masa kekuasaan Lorenzo Agung (1464-1492). Pada masa inilah, Machiavelli dilahirkan dan dibesarkan. Ayahnya Machiavelli adalah seorang ahli hukum yang kaya. Ayahnya bekerja sebagai pegawai pemerintah pada kantor pajak. Ayahnya menghendaki Machiavelli menjadi seorang teknokrat, sementara ibunya menghendaki Machiavelli menjadi seorang rohaniwan.

Semasa 30 tahun pertama hidupnya, Machiavelli mengalami sendiri beberapa kali pergantian kepemimpinan Firenze. Pada masa kepemimpinan Lorenzo, kota Firenze berkembang luar biasa, dari segi budaya, pedagangan, ilmu pengetahuan, teknologi dan sebagainya. Tidak dapat disangkal, gerakan humanisme di masa itu adalah andil Lorenzo, salah seorangnya. Selepas Lorenzo wafat (1492), kekuasaan Firenze diserahkan kepada putranya; Pietro de'Medici. Gaya pemerintahan amat berbeda dengan ayahnya. Akibatnya, muncul penentangan dari kalangan banyak, khususnya para rohaniwan biara Dominikan, yang dipimpin oleh Girolamo Savonarola. Pengaruh humanisme yang telah ditanamkan oleh ayahnya Pietro, ternyata itu hanya berpengaruh di kalangan bangsawan saja, tidak sampai pada rakyat jelata. Akibat dari pidato-pidato yang bernada antisekularisme yang diusung oleh pengaruh humanisme, Savoranola berhasil memengaruhi rakyat jelata. Berkat bantuan tangan asing, Perancis, Savoranola berhasil menyingkirkan Pietro de'Medici dari Firenze.

Di kedua masa itulah, Machiavelli menyaksikan 2 macam kekuasaan yang pernah menguasai Firenze. Keluarga Medici menerapkan kekuasaan yang berwatak sekuler dan humanis, namun hanya karena standar kekuasaan yang berkualitas rendah, kekuasaan keluarga Medici yang sudah berlangsung ratusan tahun, harus berakhir dengan mengenaskan. Sementara, Savoranola memimpin Firenze dengan gaya yang teokratis. Gaya politiknya yang demikian tidak mendapatkan dukungan dari kalangan bangsawan. Reformasi Savoranola hanya bertahan 4 tahun saja. Ia pun tersingkir. Disinilah, Machiavelli menyaksikan stabilitas kekuasaan amat menentukan, sebagaimana ia saksikan pada masa kekuasaan Lorenzo Agung.

Setelah terusirnya Medici dan kejatuhan Girolamo Savonarola di Florentine, Machiavelli mulai masuk dalam dunia politik. Sejak 1498 hingga 1512, ia ditunjuk oleh Gonfalioner Piero Soderini, pemimpin pemerintahan Florentine, bekerja sebagai sekretaris untuk kanselir kedua (second chancery) Republik Florentine, yang mengurusi 
masalah-masalah luar negara dan kebangkitan milisi sipil. Tugas misi diplomasi tidak saja dia emban di wilayah Italia, namun juga hingga keluar Italia, seperti Jerman dan Perancis. Pada 1512, Republik Florentine dijatuhkan oleh rejim Medici, yang kembali datang berkuasa disana. Tidak seperti rekan-rekannya yang masih terus diberi kesempatan untuk menduduki kursi kekuasaan, Machiavelli bernasib sebaliknya, ia dipaksa mundur. Dia menepi di sebuah kawasan terpencil di Firenze, dan hidup dalam keterbatasan secara finansial. Selepas itu, sejak 1513 hingga 1527, Machiavelli menikmati masa pensiunnya dengan menulis.

Tulisan-tulisan Machiavelli secara kategoris terbagi dalam 2 lingkup yang berkaitan satu sama lainnya. Pertama, tulisan-tulisannya sebagai kanselir yang berupa laporan-laporan, catatan-catatan (memoranda) dan tulisan-tulisan diplomatik. Kedua, karya tulis yang berupa buku, diantaranya Il principe (1513), Discorsi sopra la prima deca di Tito Livio (1517), ${ }^{14}$ Art of War (1520), dan Florentine Histories (1525). Selain itu, ia menulis sajak-sajak dan drama komedi yang dituangkan dalam Mandragola (1518).

Il principe dibuat berdasarkan pengamatan Machiavelli pada pola manajemen kekuasaan yang dijalankan Cesare Borgia, putra sulung dari Alexander VI dengan Vannoza de Cateneis. Borgia secara luar biasa memanfaatkan secara licik kedudukan ayahnya yang kemudian menjadi Paus. ${ }^{15}$ Machiavelli berharap dengan menulis ia memiliki kesempatan untuk kembali dalam kursi kekuasaan di Firenze. Bukunya berjudul Il principe sesungguhnya didedikasikan pada Lorenzo de'Medici, keponakan dari Paus Leo X dan penguasa yang

14 Discorsi dianggap sebagai salah satu karya yang mendasari gagasan republikanisme. Machiavelli memercayai gagasannya ini dapat memajukan Roma yang kuno. Lihat hal ini dalam Vickie B. Sullivan, "Machiavelli, Hobbes and the Formation of Liberal Republicanism in England”, (Cambridge: Cambridge University Press, 2004), hal. 31 et seqq.

${ }^{15}$ Kedua tokoh ini disinyalir punya hubungan yang unik karena satu sama lainnya sama-sama saling membutuhkan. Ada satu bukti yang sampai sekarang masih kontroversial, ketika Borgia mendiktekan Machiavelli untuk menulis sebuah surat perintah penangkapan. Surat itu ditandatangani oleh Borgia yang saat itu berada di Roma, namun yang mengejutkan pada 3 May 1503, ketika surat itu dibuat, Machiavelli diketahui kemudian berada di Tuscany, bukan di Roma. Tidak jelas kenapa ini bisa terjadi; apakah karena pemalsuan tandatangan atau karena alasan lain? Apapun alasannya, agak sukar kita terima sebuah alasan yang mengatakan bahwa surat itu dibuat di Tuscany dan kemudian dikirim ke Roma, untuk ditandatangani oleh Borgia. Ini agak memakan waktu, apalagi untuk urusan yang mendesak seperti itu. Lihat tulisan Renzo Sereno, A Falsification by Machiavelli, Renaissance News, Vol. 12, No. 3 (Autumn, 1959), hal. 159-167. 
sesungguhnya kawasan Firenze. Sementara Discorsi didedikasikan untuk kelompok penguasa parlemen Florentine. Bukunya History of Florence sendiri ditulis berdasarkan saran Kardinal Giulio de'Medici, yang pada 1523 menjadi Paus Clement VII. Upaya Machiavelli ini pada sekitar tahun 1520an mulai membuahkan hasil. Paus Clement VII memercayainya untuk menjabat beberapa tugas politik yang tidak terlalu penting, dan Machiavelli mendedikasikan secara sungguhsungguh pada penugasan ini, dan karenanya ia memutuskan untuk menunda menyelesaikan proyek intelektualnya. Sayangnya pada 1527, pada saat posisinya belum sungguh-sungguh mapan secara politik, dan kebetulan pada saat yang hampir bersamaan rejim Medici sekali lagi disingkirkan kembali, Machiavelli tutup usia pada 22 Juni 1527.

\section{B. Pandangan Filosofis Machiavelli ${ }^{16}$}

Sebelum kita membahas gagasan filosofis Machiavelli, kita harus meletakkan keberadaan pemikiran Machiavelli sesuai dengan konteks historisnya. Machiavelli adalah salah seorang filosof diantara para pendobrak tradisi filsafat Abad Pertengahan yang dipengaruhi oleh cara pandang yang metafisis. Metafisika yang paling kuat di masa itu dipengaruhi oleh Gereja Katolik. Bukti itu bisa dilihat dari banyaknya karya-karya intelektual atau filsafat yang dibuat oleh churchmen, termasuk juga karya-karya ecclesiastical philosopy yang dibuat oleh para pujangga Gereja. ${ }^{17}$ Pada masa itu, peradaban yang usang dimasa lalu diperbarui dengan semangat baru. Pembaruan ini terjadi di berbagai bidang, diantaranya seni dan ilmu pengetahuan. Tujuan pembaruan itu pada mulanya dilakukan oleh para humanis Italia adalah untuk mendapatkan kesempurnaan pandangan hidup yang masih berwatak kristiani. Namun yang membedakan pemikiran Renaissance dengan Abad Pertengahan, pada masa Renaissance, perhatian atas realitas hidup itu bersifat lebih kongkrit daripada yang

${ }^{16}$ Disarikan dari Nicolo Machiavelli, "The Prince", transl. Peter Bonadella (Oxford: Oxford University Press, 2005) passim. Mikael Hörnqvist, "Machiavelli and Empire", (Cambridge: Cambridge University Press, 2004), Frederick Copleston, "A History of Philosophy Volume III: Late Medieval and Renaissance Philosophy", (New York: Doubleday, 1953), hal. 310 et seqq. dan F. Budi Hardiman, "Filsafat Modern", hal. 17 et seqq.

17 Lihat dalam Bertrand Russel, "A History of Western Philosophy: And Its Connection with Political and Social Circumtances from the Earliest Times to the Present Day", (New York: Simon and Schuster, 1945), hal. 301 et seqq. 
terjadi pada masa Abad Pertengahan. ${ }^{18}$ Implikasinya, hal-hal abstrak dan mistis dari agama itu mulai dijauhkan, dan gagasan yang lebih berpusat pada diri manusia, itu lebih mengemuka saat itu. Benih-benih individualisme, dengan demikian, mulai mendapatkan tempat dalam pemikiran filsafat.

Dengan demikian, Machiavelli adalah seorang filosof yang hidup di masa kejayaan pemikiran humanis Renaissance dan kemunduran pemikiran Gereja Katolik. Dan dampak dari situasi ini terjadi pada diri Machiavelli juga. ${ }^{19}$ Oleh sebab itu, amat pantas jika Machiavelli kemudian disebut sebagai Sang Realis. ${ }^{20}$ Sebutan itu diberikan karena nanti kita akan menyaksikan bagaimana ia mengkonsepsikan pemikiran filsafatnya secara realistis, bukan suatu filsafat yang dipenuhi dengan ide-ide yang abstrak apalagi metafisis. Dalam situasi demikian, posisi agama dihadapan Machiavelli itu bukan dilihat dari segi-segi idealnya, yang mengandung pesan-pesan teologis bagi umat manusia. Bagi Machiavelli, yang penting dari agama adalah bahwa agama bisa menjadi faktor dalam politik. Agama bisa menjadi faktor yang mengintegrasikan suatu negara, agama pun bisa menjadi pendukung patriotisme dan menguatkan pranata-pranata kebudayaan. Posisi Machiavelli yang demikian itu menandakan bahwa dalam melihat hubungan antara politik dalam suatu negara dengan agama, ia mengandaikan hubungan itu bersifat sekuler. ${ }^{21}$ Disinilah titik penting karakter moderen dalam pemikiran Machiavelli. ${ }^{22}$

${ }^{18}$ Perihal filsafat Abad Pertengahan, lihat dalam Jorge J. E. Garcia, "Philosophy in Middle Ages: An Introduction", A Companion to Philosophy in Middle Ages, ed. Jorge J. E. Garcia and Timothy B. Noone (Oxford: Blackwell Publishing Ltd., 2002), hal. 1-11. Fakta kongkrit pada masa itu, dapat dilhat dari lahirnya berbagai macam eksperimen dan penemuan yang dibuat, misalnya, oleh N. Copernicus, J. Kepler, dan G. Galilei dalam bidang sains. Lihat dalam K. Bertens, "Ringkasan Sejarah Filsafat", (Yogyakarta: Penerbit Kanisius, 1975), hal. 44.

19 Dampak itu terjadi juga secara bersamaan dalam bidang filsafat dan tokohtokohnya, seperti F. Bacon dalam bidang filsafat ilmu, dan T. Moore serta H. Grotius dalam bidang filsafat hukum dan negara. Lihat dalam Harun Hadiwijono, "Sari Sejarah Filsafat Barat 2", (Yogyakarta: Penerbit Kanisius, 1980), hal. 11-17.

${ }^{20}$ Lihat dalam F. Budi Hardiman, "Filsafat Modern: dari Machiavelli sampai Nietzsche", (Jakarta: Gramedia Pustaka Utama), hal. 15.

${ }^{21}$ Walaupun demikian, sekularisme yang dia ajukan itu, menurut Alfred H. Lloyd, berbeda dengan pandangan Martin Luther dalam melihat posisi sekularisme dan spiritualisme Gereja. Bagi Machiavelli, sekularisme dan spiritualisme adalah dua entitas yang terpisah. Berbeda dengan Luther, walaupun Luther menerima sekularisme, namun menurutnya, 
Sementara itu, Machiavelli menyatakan juga bahwa dalam diri setiap manusia terdapat kepentingan-kepentingan yang tidak rasional. Manusia bisa terombang-ambing dalam emosinya masing-masing. Oleh sebab itu, setiap penguasa sesungguhnya bisa membentuk opini umum masyarakatnya, jikalau si penguasa memahami bagaimana caranya memobilisasi emosi dari tiap-tiap orang, agar senantiasa kekuasaannya makin kokoh. Dalam konteks seperti itulah, seorang penguasa harus memerhatikan bahwa alasan-alasan moral itu tidak diperlukan apabila kekuasaannya dapat langgeng. Penguasa bisa saja bersikap seolah-olah moralistis, tapi pada ujungnya, semua yang dilakukan harus demi kekuasaannya. Machiavelli mengatakan juga jikalau kekuasaan seorang penguasa itu hendak dilanggengkan, bukan hukum yang bisa menjawab kepentingan itu. Hukum menurut Machiavelli dianggap sebagai hal yang bersifat moralistis, karena ia memberikan sanksi atas setiap pelanggaran, tapi ia tidak tentu menjamin bahwa kekuasaan si penguasa dalam suatu negara akan tetap langgeng. Oleh sebab itu, yang ditawarkan oleh Machiavelli adalah sekian resep untuk menjaga kekuasaan; dari pembatalan sepihak terhadap suatu perjanjian yang telah disepakati dengan-penguasa lain, memihak kepada kekuatan yang lebih kuat dalam perang, agar mendapatkan pampasan perang yang lebih besar, hingga menyingkirkan orang-orang yang cerdik dari lingkaran kekuasaannya, ${ }^{23}$ dan menempatkan orang-orang yang patuh kepada si penguasa. Kekuasaan harus dipandang dalam kerangka dan tujuan yang nyata; bagaimana menguasai dan merawat kekuasaan selanggeng mungkin. Jadi semua konsep tentang otoritas atau hak-hak kepenguasaan tidak dianggap sebagai sebuah efek yang positif, jikalau itu tidak berujung pada pelanggengan kekuasaan. Maka itu, apa saja yang bernuansa moral, itu dianggap tidak penting oleh Machiavelli, apalagi nuansa itu tidak memberikan keuntungan politik apapun bagi si penguasa. Ringkasnya, apa yang disampaikan oleh Machiavelli itu

sekularisme memiliki tugas untuk melayani spiritualisme. Ada keterpisahan diantara keduanya, tapi yang pertama harus berfungsi melayani yang kedua. Lihat dalam Alfred $\mathrm{H}$. Llyod, Luther and Machiavelli; Kant and Frederick, The Journal of Philosophy, Psychology and Scientific Methods, Vol. 6, No. 9 (Apr., 1919), hal. 225-236.

${ }^{22}$ Bdk. Donaid McIntosh, The Modernity of Machiavelli, Political Theory, Vol. 12, No. 2 (May, 1984), hal. 184-203.

${ }^{23}$ Kalau perlu hal ini dilakukan dengan cara pembunuhan. Bdk. Charles D. Tarlton, Political Desire and the Idea of Murder in Machiavelli's "The Prince", Philosophy, Vol. 77, No. 299 (Jan., 2002), hal. 39-66. 
adalah sebuah traktat politik yang bersifat praktis, dimana pesannya tidak berisikan apa yang benar atau salah dari segi moral, namun berupa anjuran-anjuran praktis yang perlu diketahui oleh setiap penguasa untuk menjaga dan merawat kekuasaannya. ${ }^{24}$

Pandangan Machiavelli yang sekuler dalam politik dan sikapnya yang kritis atas moral tadi, secara fundamental turut memengaruhi pandangannya tentang pemimpin dan negara. Pandangannya tentang negara layak diberikan apresiasi secara khusus, karena ia adalah salah satu pelopor yang penting dalam membangun sebuah konsep moderen mengenai negara. Baginya, negara adalah sebuah konsep yang bersifat impersonal; negara bukanlah pribadi. ${ }^{25}$ Ia tidak melihat negara itu sebagai hal yang melekat dalam diri orang per orang. Entitas negara sudah menjadi sebuah entitas publik; dimiliki secara bersama-sama. Selain bersifat demikian, Machiavelli mengkonseptualisasikan lebih lanjut bahwa negara adalah sebuah bentuk yang terbatasi dalam suatu teritori dan memiliki kekuasaan yang koersif.

Berlainan dengan negara, Machiavelli menekankan segi personalitas dalam diri pemimpin. Seorang pemimpin itu dapat berkuasa hanya apabila si pemimpin itu memahami secara tepat tentang pentingnya keterampilan dan bakat atau kekuatan yang diperlukan oleh seorang pemimpin dalam memimpin. Oleh sebab itu, kekuasaan yang dipahami oleh Machiavelli, tidak mungkin akan kuat dengan hanya mengandalkan kekuatan warisan atau dukungan rakyat semata. Dengan demikian, faktor pribadi adalah faktor penting dalam diri pemimpin, karena ia telah meletakkan suatu asumsi bahwa negara itu adalah sebuah bentuk yang impersonal. Oleh sebab itu, setiap pemimpin harus memahami setiap aspek teknis dan menguasainya agar si pemimpin dapat mengelola kekuasaan politik dengan tepat. Keterampilan, dengan demikian, menjadi kata kunci yang utama dalam diri seorang pemimpin. Seorang pemimpin harus mampu menggunakan seluruh kekuasaannya agar kekuasaannya terjaga senantiasa. Oleh sebab itu, dengan posisi demikian, Machiavelli meletakkan gagasannya tentang pemimpin dalam posisi yang

${ }^{24}$ Bdk. William R. Thayer, Machiavelli's Prince, International Journal of Ethics, Vol. 2, No. 4 (Jul., 1892), hal. 476-492.

25 Pikirannya ini dikembangkan secara lebih sistematis oleh Montesquieu. Montesquieu mengenalkan gagasan tentang sistem pemisahan kekuasaan (separation of powers) yang pada pokoknya memastikan bahwa kekuasaan itu teralokasi secara personal dalam diri individu atau kelompok. Bdk. Sharon Krause, The Spirit of Separate Powers in Montesquieu, The Review of Politics, Vol. 62, No. 2 (Spring, 2000), hal. 231-265. 
kontroversial. Bagi Machiavelli, seorang pemimpin diantaranya harus memahami bagaimana caranya meluaskan dan mempertahankan wilayah kerajaannya, lalu ia pun harus dapat menggunakan kejahatan yang tidak berlanjut dalam merebut negara. Lalu, menurutnya, seorang pemimpin pun harus memiliki kemampuan berperang yang memadai agar rakyat menaruh rasa segan padanya, seorang pemimpin pun harus cerdik dan lihai agar ia tidak terbuai dengan muslihat kekuatan asing yang bisa merugikan kekuasaannya dan seterusnya.

\section{Refleksi dan Kritik Terhadap Proyek Filsafat Machiavelli}

\section{Refleksi Filosofis atas Tafsir Distortif Proyek Filsafat Machaivelli}

Tentu, pandangan politiknya yang demikian telah memancing polemik. Sebagian mengatakan bahwa apa yang disampaikan adalah sebuah anjuran politik yang dapat diartikan secara salah, karena didalamnya mengandung berbagai macam muslihat politik. Pendapat itu semakin bisa dimengerti apabila kita mendapati bahwa pengertian virtù yang disampaikan oleh Machiavelli dalam bukunya, Il principe, itu berbeda dengan pengertian virtue yang dipahami secara awam. Virtù menurut Machiavelli adalah suatu istilah yang bersifat teknis; sebuah kemampuan yang praktis untuk mencapai suatu tujuan. Oleh sebab itu, istilah ini tidaklah normatif, tidak mengandung nilainilai ideal sebagaimana yang dimaksud dalam pengertian virtue. ${ }^{26}$ Oleh sebab itu, ia tidak melihat bahwa moralitas dan juga hukum menjadi sebuah resep yang mujarab untuk melanggengkan kekuasaan. Bagi Machiavelli, resep yang mujarab untuk menjawab kebutuhan akan kekuasaan yang stabil adalah keterampilan teknis dari si penguasa itu sendiri. Jikalau si penguasa memiliki kemampuan tersebut dan mampu untuk memanfaatkannya, maka kekuasaan akan terjaga sebagaimana yang ia kehendaki.

Jika kita kembali lagi kepada sikap resisten Machiavelli terhadap segala hal yang berwatak etis atau normatif, maka kita kemudian menemukan bahwa eksistensi agama pun ditolak oleh Machiavelli. Namun, penolakannya ini juga disebabkan oleh

26 Lihat John Leonard, Public versus Private Claims: Machiavellianism from Another Perspective, Political Theory, Vol. 12, No. 4 (Nov. 1984), hal. 491-506. 
sebuah kenyataan yang ia saksikan dan refleksikan sendiri, bahwa realitas politik itu bukan ditentukan oleh agama. Ia mengatakan demikian karena ia meyakini bahwa zaman telah bergeser dan berubah; hal-hal yang berbau atau bernuansa metafisis atau mistis telah mulai ditinggalkan saat itu. Disini kita melihat bahwa tangkisan ia terhadap agama, pertama-tama disebabkan -oleh keyakinannya bahwa era baru yang tidak metafisis dan tidak mistis telah lahir, disamping itu, kita bisa melihat bahwa sikapnya ini konsisten dengan penolakan Machiavelli pada hal-hal yang etis atau normatif karena semua itu tidak menjawab tantangan politik secara nyata.

Meskipun pendirian Machiavelli demikian, tidaklah tepat kita mengatakan bahwa apa yang ditulis oleh Machiavelli itu melulu berisikan anjuran-anjuran politik praktis yang dituding berkesan negatif secara etis. Dalam bukunya, The Prince - dan juga Discourse - Machiavelli menganjurkan kepada para penguasa memiliki sikap politik yang simpatik, agar tidak ada celah terjadinya konspirasi terhadap si penguasa. Perempuan tidak boleh dijadikan layaknya properti. Penguasa pun harus memiliki kualitas kepemimpinan yang tepat, ketulusan, kedermaan dan sebagainya, karena tanpa itu semua, kekuasaannya akan runtuh dengan sendirinya. ${ }^{27}$ Disini kita bisa merefleksikan bahwa ia memang sungguh-sungguh seorang realis dalam memandang apa itu kekuasaan. Oleh sebab itu pula, tidaklah benar, bahwasanya Machiavelli adalah seorang pemuja kekuasaan yang menganjurkan cara-cara yang menghalalkan segala cara untuk merawat kekuasaan. Ia pun ternyata dibalik itu menganjurkan cara yang simpatik untuk merawat kekuasaan ditangan penguasa.

Kesalahpahaman itu bisa terjadi jika kita memahaminya secara parsial tanpa memerhatikan konteks sejarah pada saat itu. Apabila kita perhatikan sejarah Italia pada masa itu, Machiavelli menjumpai beberapa gejolak politik yang terjadi di Napoli, Milan, Venice, Pisa dan termasuk Firenze. Berkat situasi yang demikian, Machiavelli menawarkan suatu proposal tentang pentingnya caracara untuk menjaga kekuatan dan keberlangsungan suatu negara. Oleh sebab itu, dimata Machiavelli, persoalan kenegaraan itu semata-mata disusun atas kepentingan dan manfaat yang nyata, bukan karena alasan-alasan ideal yang moralistis sifatnya. Disini,

27 Lihat dalam G. H. R. Parkinson, Ethics and Politics in Machiavelli, The Philosophical Quaterly, Vol. 5, No. 18 (Jan., 1955), hal. 37-44. 
kita bisa melihat bahwa Machiavelli berpandangan utiliter dan tidak ideal, dalam memandang politik, karena jatuh bangunnya suatu negara itu tidak bersifat pra-determinasi; ditentukan sepenuhnya oleh kuasa Tuhan atau kekuasaan yang mistis. Itu bisa terjadi hanya dikarenakan oleh sebuah kemampuan politik yang nyata dan rasional. Disinilah proyek filsafat Machiavelli sesungguhnya yang telah melampaui zaman.

\section{Kritik atas Proyek Filsafat Machiavelli}

Dibalik mispersepsi tersebut, ada beberapa titik kritis yang sesungguhnya perlu diajukan disini.

Pertama, Machiavelli melihat bahwa ada relasi masyarakat secara struktural dalam karya-karyanya. ${ }^{28}$ Tapi pemaparannya itu nampak sederhana, jikalu tidak disebut simplistis. Ia tidak menjelaskan apa yang menjadi dasar bekerja adanya relasi itu. Machiavelli misalnya, tidak menjelaskan bahwa ada relasi yang ideologis sifatnya berdasarkan relasi hubungan dan faktor produksi, dan termasuk implikasi dari relasi tersebut, sebagaimana disampaikan oleh Karl Marx. ${ }^{29}$ Machiavelli hanya sebatas menjelaskan adanya kelas bangsawan dan pariah berikut konflikkonflik yang terjadi antarkelas, ${ }^{30}$ dan terkesan membela kepentingan kaum ningrat/bangsawan. Kerangka analisa struktural Machiavelli yang demikian sederhana, bisa dipahami karena situasi sosial-ekonomi pada masa itu belum sekompleks saat Karl Marx memproduksi analisa strukturalnya. Atau dengan kata lain, proletarisasi belum terbentuk sempurna dan kaum bangsawan masih menjadi kelas penguasa, sehingga antagonisme kelas yang dilihat oleh Machiavelli hanyala peta kelas bangsawan-pariah. Walaupun demikian, analisa struktural Machiavelli tersebut tidak dapat disangkal lagi telah menjadi salah satu bukti ilmiah yang otentik tentang suatu metode analisa kelas yang saat ini amat lazim dikenal.

${ }^{28}$ Lihat Kent M. Brudney, Machiavelli on Social Class and Class Conflict, Political Theory, Vol. 12. No. 4 (Nov., 1984), hal. 507-519.

${ }^{29}$ Penjelasan yang sederhana mengenai hal ini dapat dilihat dalam Franz MagnisSuseno, "Pemikiran Karl Marx: Dari Sosialisme Utopis ke Perselisihan Revisionisme", (Jakarta: Gramedia Pustaka Utama, 2001), hal. 110 et seqq.

${ }^{30}$ Ibid. 
Kedua, uraian Machiavelli tidak memiliki perspektif yang baik tentang perempuan. Itu bisa dilihat ketika ia menguraikan istilah virtù. Secara etimologis, istilah itu mengandung suatu pengertian mengenai suatu karakter yang melekat pada vir; warga negara lelaki. ${ }^{31}$ Walaupun oleh Gadis Arivia, Machiavelli tidak dimasukkan dalam kategori filosof yang bias dalam hal jender, alam pikir Machiavelli tidak mungkin tercerabut dari pengaruh filsafat moderen pada masa itu, yang menurut Gadis Arivia, memang bias secara jender. ${ }^{32}$ Alam pikir yang demikian tentu saja memberikan implikasi pada gagasan politik Machiavelli yang tidak condong pada eksistensi perempuan karena alam pikir pada masa itu masih menokohkan eksistensi pria dalam ranah filsafat dan politik. Oleh sebab itu, Machiavelli masih meyakini bahwa hanya pria yang mampu menjadi aktor politik.

\section{Penutup}

Apapun pembelaan akademis yang telah diberikan oleh beberapa pihak terhadap Machiavelli, namun tetap saja, sangkaan publik terhadap Machiavelli yang berkesan negatif lebih kuat. ${ }^{33}$ Sangkaan yang negatif ini bisa dipahami, karena menurut John H. Geerken, Machiavelli adalah seorang multidimensional. Menurut Geerken, Machiavelli adalah sekaligus: ${ }^{34}$

... the father of modern political science, of metapolitics and raison d'etat, the father of heroic morality and modern comedy, of Machiavellism and anti-Machiavellism, the father of radical, critical, naturalistic humanism; and a father of modern Italian

${ }^{31}$ Lihat dalam Terence Ball, "The Picaresque Prince: Reflections on Machiavelli and Moral Change", Political Theory, Vol. 12, No. 4 (Nov., 1984), hal. 521-536.

${ }^{32}$ Machiavelli adalah filosof Abad moderen - yang tokoh-tokohnya adalah Rene Descartes, Francis Bacon, Thomas Hobbes, John Locke, David Hume, Jean Jacques Rousseau, Immanuel Kant, Georg Hegel, Arthur Schopenhaue, John Stuart Mill dan Friederich Nietzsche - yang amat terpengaruh dengan gagasan filsafat yang maskulin. Lihat Gadis Arivia, Filsafat Berperspektif Feminis (Jakarta: Yayasan Jurnal Perempuan, 2003), hal. 37-57.

${ }^{33}$ Bdk. Guglielmo Ferrero, "Machiavelli and Machiavellism", Foreign Affairs, Vol. 17, No. 3 (Apr., 1939), hal. 569-577.

${ }^{34}$ John H. Geerken, "Machiavelli Studies since 1969", Journal of the History Ideas, Vol. 37, No. 2 (Apr. - Jun., 1976), hal. 351-368. 
nationalism. He is the patriot-teacher of republican liberty, but also of despotism, terrorism, and absolutism; the bona fide teacher of bad faith; the architect of a great spiritual crisis (comparable to that of Luther's in the religious realm); the detheologizer of Original Sin; the de-mythologizer of political theory; the master-analyst of the human heart; the first ruthless anatomist of the historical condition; the first to form the theory of political collaboration; the discoverer of the pathos of political technique; the first theorist of the fifth column; the precursor of a sociotecnica and of a praxeologie mathematique. He is Machiavelli the atheist, positivist, naturalist, realist, existentialist, pragmatist, and scientist; he is Machiavelli the Christian, the proto-Jesuit, proto-fascist, proto-Marxist; Machiavelli the Jacobin, the Jansenist, the bourgeois, the revolutionary. He is the Galileo of politics, the hero-artist of pure politics, the tragic poet of power politics, the philologist of certainty without truthfulness, the intellectual godfather of heretics. Father, husband, citizen, partisan, Chancery Secretary, diplomat, historian, and playwright-he is Machiavelli the radical enigma. Like the intellectual continent he is credited with discovering, he has himself become a continent, and one whose topography becomes increasingly difficult to chart: his genealogy, early life, personality, and career; his political activities and theoretical concerns; his understanding and use of history; his style and use of language; his method; his religiosity; his interest in and knowledge of Livy, Tacitus, Terence, Plutarch, Xenophon, and other ancient writers; his ties to Dante, Vettori, Soderini, Borgia, and other contemporaries or near-contem-poraries; his ever-widening influence on those who came after him-from Montaigne, Descartes, Vico, and Rousseau to Spinoza, Manzoni, Leopardi, and Marx; his attitudes towards Rome, Florence, Venice, and France; his views on the Turks; his antecedents in ancient China; his influence in the Islamic world, in Latin America and the United States, in England, Denmark, Russia, Poland, and Japan-such are the principal features of this continent explored in and since 1969.

Padahal jika, sekali lagi, memerhatikan konteks historis yang mengiringi pemikiran Machiavelli, kita bisa mendapat persepsi yang berbeda. Apa yang disampaikan oleh Machiavelli telah melampaui 
zamannya, dan dianggap sebagai hal yang baru bagi kebanyakan orang; ${ }^{35}$ sebuah proyek filsafat politik yang telah melepaskan dirinya dari motif teologis dan moral. Oleh sebab itu, apa yang Machiavelli telah sampaikan itu berkesan sebagai sebuah perlawanan yang didorong oleh motif atau insting belis, karena berbeda sama sekali dengan kelaziman gagasan politik pada masa itu. Padahal, sesungguhnya, Machiavelli hendak mengajak kita untuk lebih realistis dalam memandang politik; tidak terjebak dalam hal-hal yang tidak rasional secara politik. Dihadapan Machiavelli, politik tidak lagi datang dari wahyu yang berasal dari langit. Politik seperti itu telah berakhir. Baginya, politik adalah sebuah realitas. Itulah refleksi filosofis yang ia tawarkan. Oleh sebab itu, menuding Machiavelli dalam teks-teks akademis - apalagi yang selama ini tersedia dalam literatur hukum - dengan segala macam atribut yang negatif, adalah serangkaian tudingan ahistoris yang harus ditinjau kembali, mengingat seluruh tudingan itu kurang dibangun diatas dasar refleksi filosofis yang komprehensif.

Daripada terhuyung-huyung terus dalam arus tudingan negatif yang demikian, kita seharusnya mencoba merefleksikan kontribusi Machiavelli dalam studi hukum, politik dan filsafat. Kontribusi Machiavelli disini adalah, pertama, Machiavelli telah meletakkan suatu studi yang moderen mengenai politik dan negara. Ia boleh dikatakan telah memoderenisasikan seluruh pemahaman klasik tentang politik dan negara. Kedua, Machiavelli telah menjadi salah satu peletak analisa dan metode strukturalis dalam memandang dan memahami peta sosial dan politik dalam suatu masyarakat atau negara.

${ }^{35}$ Bdk. Louis Althusser, "Machiavelli and Us", (London: Verso, 1999), hal. 6. 


\section{Daftar Pustaka}

\section{Buku}

Althusser, Louis. Machiavelli and Us. London: Verso, 1999.

Arivia, Gadis. Filsafat Berperspektif Feminis. Jakarta: Yayasan Jurnal Perempuan, 2003.

Azhary. Negara Hukum Indonesia: Analisis Yuridis Normatif tentang UnsurUnsurnya. Jakarta: Penerbit Universitas Indonesia, 1995.

Bernard, John. Why Machiavelli Matters: A Guide in Citizenship in a Democracy. Westport: Praeger Publishers, 2009.

Bertens, K. Ringkasan Sejarah Filsafat. Yogyakarta: Penerbit Kanisius, 1975.

Bunin, Nicholas and Jiyuan Yu, The Blackwell Dictionary of Western Philosophy. Malden: Blackwell Publishing Ltd., 2004.

Copleston, Frederick. A History of Philosophy Volume III: Late Medieval and Renaissance Philosophy. New York: Doubleday, 1953.

Djokosutono. Ilmu Negara, ed. Harun Al Rasyid. Jakarta: Ghalia Indonesia, 1982.

Garcia, Jorge J. E. Philosophy in Middle Ages: An Introduction, A Companion to Philosophy in Middle Ages, ed. Jorge J. E. Garcia and Timothy B. Noone. Oxford: Blackwell Publishing Ltd., 2002.

Hardiman, F. Budi. Filsafat Modern: dari Machiavelli sampai Nietzsche. Jakarta: Gramedia Pustaka Utama, 2001.

Hadiwijono, Harun. Sari Sejarah Filsafat Barat 2. Yogyakarta: Penerbit Kanisius, 1980.

Hörnqvist, Mikael. Machiavelli and Empire. Cambridge: Cambridge University Press, 2004.

Hutauruk, M. Azas-Azas Ilmu Negara. Cetakan ke-3 yang direvisi. Jakarta: Penerbit Erlangga, 1983.

King, Ross. Machiavelli: Philosopher of Power. London: HarperCollins, 2007.

Kranenburg, R. dan Sabaroedin, Tk. B. Ilmu Negara Umum. Cetakan Kesebelas. Jakarta: Pradnya Paramita, 1989. 
Kusnardi, Moh. dan Saragih, Bintan R. Ilmu Negara. Edisi Revisi. Jakarta: Penerbit Gaga Media Pratama, 1995.

Lubis, M. Solly. Ilmu Negara. Cetakan ke-IV. Tanpa tempat: Penerbit Mandar Maju, 1990.

Machiavelli, Nicolo. The Prince, transl. Peter Bonadella. Oxford: Oxford University Press, 2005.

Magnis-Suseno, Franz. Pemikiran Karl Marx: Dari Sosialisme Utopis ke Perselisihan Revisionisme. Jakarta: Gramedia Pustaka Utama, 2001.

Manullang, E. Fernando M. Korporatisme dan Undang-Undang Dasar 45: Intrepretasi Hukum Terhadap Teks Undang-Undang Dasar 1945 dan Risalah Sidang Badan Penyelidik Oesaha ${ }^{2}$ Kemerdekaan (BPUPK) dan Panitia Persiapan Kemerdekaan Indonesia (PPKI) tentang Pengaruh Nilai Korporatisme dalam Undang-Undang Dasar 1945. Bandung: Nuansa Aulia, 2010.

Nurtjahjo, Hendra. Ilmu Negara: Pengembangan Teori Bernegara dan Suplemen. Jakarta: RajaGrafindo Persada, 2005.

Parrel, Anthony J. Machiavelli, Nicollo, Cambridge Dictionary of Philosophy, Second Edition, ed. Robert Audi. Cambridge: Cambridge University Press, 1999.

Ratcliffe, Susan (ed.), People on People: The Oxford Dictionary of Biographical Quotations. Oxford: Oxford University Press, 2001.

Russel, Bertrand. A History of Western Philosophy: And Its Connection with Political and Social Circumtances from the Earliest Times to the Present Day. New York: Simon and Schuster, 1945.

Schmid, J. J. von. Grote Denkers over Staat en Recht (van Plato tot Kant), atau Ahli2 Pemikir Besar tentang Negara dan Hukum (dari Plato sampai Kant), terj. Wiratno dan Djamaluddin Dt. Singomangkuto. Jakarta: Pembangunan, 1959.

Sullivan, Vickie B. Machiavelli, Hobbes and the Formation of Liberal Republicanism in England. Cambridge: Cambridge University Press, 2004. 


\section{Jurnal}

Ball, Terence. "The Picaresque Prince: Reflections on Machiavelli and Moral Change", Political Theory, Vol. 12, No. 4, November 1984: 521-536.

Brudney, Kent M. "Machiavelli on Social Class and Class Conflict", Political Theory, Vol. 12. No. 4, November 1984: 507-519.

Geerken, John H. "Machiavelli Studies since 1969", Journal of the History Ideas, Vol. 37, No. 2, Apr. - Jun., 1976:. 351-368.

Gilbert, Felix. "Machiavelli, Nicolo", Encylopedia of Philosophy, Second Edition, Vol. 5, ed. Donald M. Borchert, Detroit: Thomson Gale, 2006: 626-629.

Ferrero, Guglielmo. "Machiavelli and Machiavellism", Foreign Affairs, Vol. 17, No. 3, Apr., 1939: 569-577.

Llyod, Alfred H. "Luther and Machiavelli; Kant and Frederick", The Journal of Philosophy, Psychology and Scientific Methods, Vol. 6, No. 9, Apr., 1919:. 225-236.

Krause, Sharon. "The Spirit of Separate Powers in Montesquieu", The Review of Politics, Vol. 62, No. 2, Spring, 2000: 231-265.

Leonard, John. "Public versus Private Claims: Machiavellianism from Another Perspective", Political Theory, Vol. 12, No. 4, November 1984: 491-506.

Manullang, E. Fernando M. "Ide Negara Korporatis Menurut Soepomo \& Benito Mussolini: Suatu Refleksi Kritis Atas Pengaruh dan Implikasi Gagasan Korporatisme Dalam Undang-Undang Dasar 1945", Jurnal Hukum \& Pembangunan, Tahun Ke-38, No. 2, April-Juni, 2008: 301315.

McIntosh, Donald. "The Modernity of Machiavelli", Political Theory, Vol. 12, No. 2, May, 1984: 184-203.

Parkinson, G. H. R. "Ethics and Politics in Machiavelli", The Philosophical Quaterly, Vol. 5, No. 18, Januari 1955: 37-44.

Sereno, Renzo. "A Falsification by Machiavelli", Renaissance News, Vol. 12, No. 3, Autumn, 1959: 159-167.

Tarlton, Charles D. "Political Desire and the Idea of Murder in Machiavelli's "The Prince"”, Philosophy, Vol. 77, No. 299, Januari, 2002: 39-66. 
Thayer, William R. "Machiavelli's Prince", International Journal of Ethics, Vol. 2, No. 4, Juli 1892: 476-492. 